\title{
Evaluation of polymerization ability of resin-based materials used for teeth splinting
}

\author{
Jeong-Gil Lee', Soo-Yeon Kim¹, Jae-Kwan Lee², Jin-Woo Kim', Se-Hee Park', Kyung-Mo Cho* \\ 'Department of Conservative Dentistry, College of Dentistry, Gangneung-Wonju National University, Gangneung, Republic of Korea \\ 'Department of Periodontology, Research Institute for Oral Sciences, College of Dentistry, Gangneung-Wonju National University, \\ Gangneung, Republic of Korea
}

Purpose: The aim of this study was to evaluate the polymerization ability of resin-based materials used for teeth splinting according to the thickness of cure. Materials and Methods: For this study, the Light-Fix and G-FIX developed for resinous splinting materials and the G-aenial Universal Flo, the high-flowable composite resin available as restorative and splinting material, were used. Ten specimens of the thickness of 2, 3, 4 and $5 \mathrm{~mm}$ and $5 \mathrm{~mm}$ in diameter for each composite resin (total 120) were prepared. The microhardness of top and bottom surfaces for each specimen was measured by the Vickers hardness testing machine. The polymerization ability of the composite resin for each thickness was statistically analyzed using independent T-test at a 0.05 level of significance. Results: There was no difference of polymerization ability regardless of the thickness in the Light-Fix and G-FIX. The G-aenial Universal Flo showed significantly low polymerization ability from the thickness of the $3 \mathrm{~mm}(P<0.05)$. Conclusion: The Light-Fix and G-FIX, which are resin-based materials used for teeth splinting, are expected to be suitable for light curing up to $5 \mathrm{~mm}$ in thickness. (J Dent Rehabil Appl Sci 2018;34(4):290-6)

Key words: composite resin splint; microhardness; polymerization ability; tooth mobility

\begin{abstract}
서론
치아의 비생리적 동요는 치주 질환, 치아 외상 또는 외 상성 교합 등으로 발생한다. 임상에서 심한 동요가 있는 치아는 발치를 하는 경우가 많지만, 여러 가지 이유들로 인해 치아를 유지 해야할 경우 치아 고정을 위한 스플린 트(splint) 치료가 행해진다. ${ }^{1,2}$ 스플린트는 치아의 증가된 동요를 제한하고 고정시키기 위해 두 개 또는 그 이상의 치아를 연결하는 것이다. 이는 환자의 불편감을 감소시켜 주고 교합 관계를 회복시켜 저작 기능 중에 생기는 하중 을 여러 치아로 분산시켜 유해한 측방력을 수직적인 방향 으로 바꿔줌으로써 동요 치아의 예후를 개선시켜준다. ${ }^{3}$
\end{abstract}

스플린트 치료의 임상적인 성공을 위하여 다양한 요구 조건이 제시되고 있다. 스플린팅 재료를 포함한 구강 내 의 수복물은 온습한 환경에서 장기간 저작압에 노출되 고 응력을 받게 되면서 재료 자체의 응집 실패 또는 치아 와 수복물 계면에서 부착 실패를 일으킨다. ${ }^{4}$ 그러므로 불 리한 구강 내 환경에서 파절되지 않기 위해서 높은 강도 와 법랑질에서의 믿을만한 접착 강도가 요구된다. 또한 스플린트는 치아의 생리적인 움직임을 허용할 수 있도록 낮은 탄성 계수를 지녀야 한다. ${ }^{5,6}$ 많은 연구들에서 생리 적 치아 동요를 허용하는 연성 스플린트의 이점이 보고 되고 있다. ${ }^{7-9}$

여러 스플린트 방법 중, 인접 치아의 법랑질에 직접 재 
료를 접착시켜 고정하는 레진 스플린트 방법은 치아 삭 제가 거의 필요하지 않고 술식이 용이하며 심미적으로 우수하다는 장점을 지닌다. ${ }^{7,10}$ 또한 비교적 구강위생을 방해하지 않아서 추가적인 진단 및 치료를 허용할 수 있 다. ${ }^{11,12}$ 이러한 장점들로 인해 레진 스플린트는 동요 치아 고정을 위한 스플린트 치료 중 널리 사용되는 방법이며 최근에는 레진 스플린트 치료를 위한 전용 제품이 개발 되고 출시되어 점점 사용이 증가하고 있다.

치과에서 임상적으로 사용하는 복합레진계 재료는 사 용하는 동안 조작이 용이한 무른 성질을 가지고 있다가 중합에 의해 굳게 되면 중합의 정도에 따라 물성이 다르 게 나타나는데, 일반적으로 보다 높은 중합이 되었을 때 더 우수한 물리적 성질이 나타나기 때문에 레진계 재료 의 중합 능력은 매우 중요한 요소라고 할 수 있다. ${ }^{13-15}$

현재까지 다양한 스플린트 종류에 따른 여러 기계적 성질과 그 예후에 대한 많은 연구가 발표되었다. 하지만 새로운 레진계 재료를 이용한 동요 치아 고정에 사용되 는 재료들의 물리적 성질에 대한 연구는 매우 미미하다. 또한 대부분 굴곡 강도에 대한 연구만 발표되어 있고 레 진계 재료의 중요한 특성인 중합도와 관련된 연구는 거 의 찾아볼 수 없다. 특히 최근 새롭게 시판되었거나 개발
된 제품에 관한 연구는 거의 없다. 따라서 본 연구는 스플 린트 전용으로 개발되어 나온 여러 종류의 광중합형 레 진계 재료에 대하여 다양한 두께에서의 중합 능력을 평 가하고자 하였다.

\section{연구 재료 및 방법}

\section{1. 실험 재료}

총 세 가지의 광중합 복합레진을 사용하였다. 치아 스플린트 전용으로 개발된 복합레진인 Light-Fix (Sun Medical Co., Moriyama, Japan)와 G-FIX (GC Co., Tokyo, Japan), 그리고 수복용과 스플린트용으로 사용 가 능한 고흐름성 복합레진인 G-aenial Universal Flo (GC $\mathrm{Co}$ )를 사용하였다. 각각의 구성성분은 Table 1 에 정리하 였다.

\section{2. 시편 제작}

테플론을 이용하여 직경 $5 \mathrm{~mm}$, 두께 $2 \mathrm{~mm}, 3 \mathrm{~mm}, 4$ $\mathrm{mm}, 5 \mathrm{~mm}$ 의 몰드를 제작하였다(Fig. 1). 유리판 위에 각

Table 1. Composition and shade of materials used in this study

\begin{tabular}{ccll}
\hline Material & Manufacturers & Shade & \multicolumn{1}{c}{ Composition } \\
\hline Light-Fix & Sun Medical & Clear & $\begin{array}{l}\text { Methacrylic acid ester (UDMA, 4-META, etc), acylic acid ester, } \\
\text { photo initiator }\end{array}$ \\
G-FIX & GC & Clear & $\begin{array}{l}\text { Bis-EMA, phosphoric ester monomers } \\
\text { Gatrix (31\%wt.): UDMA, Bis-MEPP, TEGDMA }\end{array}$ \\
G-aenial Universal Flo & GC & A2 & Filler (69\%wt., 50\%vol.): Silicon dioxide (16 nm), strontium glass \\
& & & Photo initiator
\end{tabular}

Data from manufacturers' websites and/or product catalogs.

UDMA; Urethane dimethacrylate, 4-META; 4-methacryloyloxyethy trimellitate anhydride, Bis-EMA; ethoxylated bisphenol-A dimethacrylate, BisMEPP; 2,2-Bis(4-methacryloxypolyethoxyphenyl) propane, TEGDMA; Triethyleneglycol dimethacrylate.

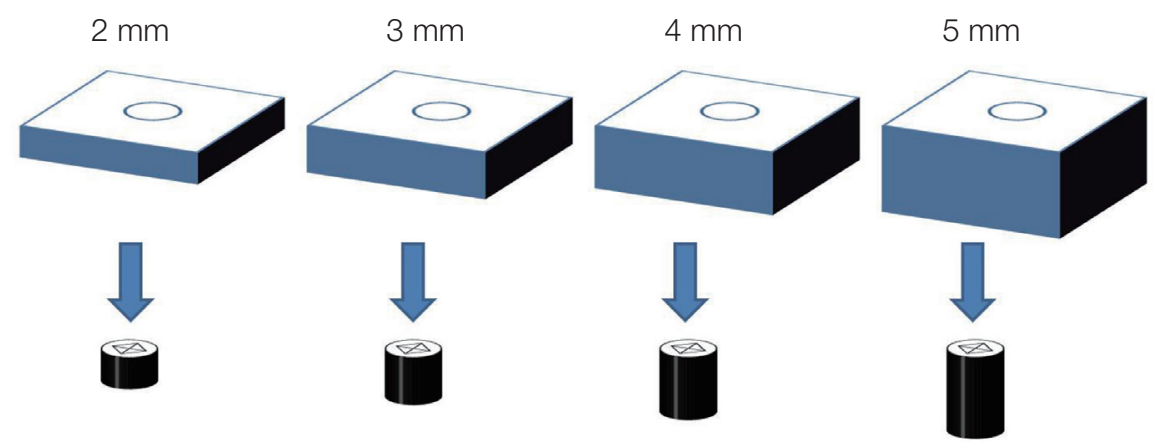

Fig. 1. Schematic drawing of the molds used for specimen fabrication. 
각의 재료들을 몰드에 채우고 상면과 하면을 mylar strip 으로 덮은 뒤 슬라이드 글라스로 가볍게 누른 다음 잉 여 재료를 제거한 후 시편의 상부에서 G-light LED 광 중합기(GC Co., Tokyo, Japan)를 이용하여 20초간 광중 합을 시행하였다. 광중합 후 상면과 하면을 표시하고 몰 드에서 시편을 제거한 뒤 24시간 동안 빛이 들어가지 않 는 $100 \%$ 상대습도 $37 \pm 1^{\circ} \mathrm{C}$ 항온기(SIB-1, Seo-Kwang Science Co., Seoul, Korea)에 보관하였다. 각 재료들마 다 두께별로 10 개씩 총 120 개 시편을 제작하였다. 광중 합기는 광도계(LED Radiometer, ThreeH, Guangzhou, China) 를 이용하여 중합 전에 광량 $\left(980 \mathrm{~mW} / \mathrm{cm}^{2}\right)$ 이 동 일함을 확인하였다.

\section{3. 미세경도 측정}

각각의 시편은 Vickers 미세경도 측정기(HM 124, Mitutoyo, Kawasaki, Japan)를 이용하여 $50 \mathrm{~g}$ 의 load로 5 초 간 측정하였다. 시편마다 오류를 최소화 하기 위해 0.1 $\mathrm{mm}$ 씩 떨어진 부위를 지정하여 3 번의 미세경도값을 측정 하고 그것들의 평균값을 계산하여 면당 미세경도로 정하 였다. 이렇게 각 시편당 상면과 하면의 미세경도를 기록 하였다.

\section{4. 통계분석}

SPSS ver 23.0 (SPSS Inc., Chicago, USA)을 사용하 여 각각의 재료들마다 두께별 상면과 하면의 중합정도를 95\% 유의수준에서 independent T-test로 비교하였다.

\section{결과}

각 재료마다 두께별 상면과 하면의 미세경도 평균값 과 표준편차, 상·하면의 미세경도를 비교하여 유의성을 Table 2에 나타내었다.

Light-Fix와 G-FIX에서 두께별 상·하면의 미세경도값 에는 유의한 차이가 없었다. 이는 Light-Fix와 G-FIX는 두께에 상관없이 중합도 차이를 보이지 않았다고 볼 수 있다.

특히 G-aenial Universal Flo의 $3 \mathrm{~mm}$ 두께 이상에서부 터는 상·하면의 미세경도값에서 유의한 차이를 보였다 $(P<0.05)$. 즉 G-aenial Universal Flo는 $3 \mathrm{~mm}$ 두께부터 낮은 중합도를 보였다고 해석할 수 있다.

\section{고찰}

임상에서 비정상적인 동요 치아를 레진 스플린트로 치 료할 때 복합레진을 치아 인접면의 순측에서 설측까지 채워 광중합을 하게 되는데, 이 때 채워진 레진의 두께는 치아 사이의 공간마다 또는 구강 내 부위마다 다르며 치 아를 통과시켜 중합을 해야하는 상황도 생기기 때문에 스플린트 치료 시 사용하는 레진의 중합 정도를 알아보 기 위해 이번 연구를 기획하게 되었다.

복합레진의 기계적 성질은 단량체의 종류와 함량, ${ }^{16}$ 필 러의 종류와 입자 크기, ${ }^{17}$ 커플링제의 종류, 개시제의 종 류와 양, ${ }^{18}$ 중합도 ${ }^{1920}$ 등에 영향을 받는다. 일반적으로 광 중합 복합레진은 $43-75 \%$ 의 중합도를 가지며 이는 단량 체의 구성, 중합 광의 강도 및 광조사 시간에 따라 다르

Table 2. Results of Vickers microhardness and significance of tested materials (Mean \pm standard deviation)

\begin{tabular}{|c|c|c|c|c|}
\hline Material & Thickness $(\mathrm{n}=10)$ & Top surface & Bottom surface & Significance \\
\hline \multirow[t]{4}{*}{ Light-Fix } & $2 \mathrm{~mm}$ & $17.38 \pm 1.02$ & $17.06 \pm 0.81$ & \\
\hline & $3 \mathrm{~mm}$ & $17.37 \pm 0.54$ & $17.37 \pm 0.34$ & \\
\hline & $4 \mathrm{~mm}$ & $17.23 \pm 0.49$ & $17.18 \pm 0.64$ & \\
\hline & $5 \mathrm{~mm}$ & $17.65 \pm 0.79$ & $17.46 \pm 0.40$ & \\
\hline \multirow[t]{4}{*}{ G-FIX } & $2 \mathrm{~mm}$ & $14.85 \pm 0.29$ & $14.87 \pm 0.43$ & \\
\hline & $3 \mathrm{~mm}$ & $15.48 \pm 0.40$ & $15.36 \pm 0.18$ & \\
\hline & $4 \mathrm{~mm}$ & $16.27 \pm 0.59$ & $16.12 \pm 0.35$ & \\
\hline & $5 \mathrm{~mm}$ & $16.76 \pm 1.03$ & $16.74 \pm 0.86$ & \\
\hline \multirow[t]{4}{*}{ G-aenial Universal Flo } & $2 \mathrm{~mm}$ & $38.50 \pm 0.62$ & $38.08 \pm 0.56$ & \\
\hline & $3 \mathrm{~mm}$ & $41.72 \pm 0.80$ & $31.43 \pm 1.16$ & $*$ \\
\hline & $4 \mathrm{~mm}$ & $39.68 \pm 0.48$ & $22.22 \pm 1.04$ & $*$ \\
\hline & $5 \mathrm{~mm}$ & $40.61 \pm 1.34$ & $15.97 \pm 0.54$ & $*$ \\
\hline
\end{tabular}

* Significant differences were detected (Independent T-test, $P<0.05$ ). 
다. ${ }^{21,22}$ 따라서 본 실험에서는 중합도에 영향을 미치는 중 합 광의 강도를 광도계를 통해 일정하도록 하였고, 광조 사 시간도 동일하게 20 초로 정하였다.

일반적으로 레진 단량체의 점도는 중합도와 반비례하 는데, 가장 점도가 높은 bisphenol A-glycidyl methacrylate (Bis-GMA)는 유동성이 떨어져 중합도를 떨어뜨 리기 때문에 제조사에서는 광조사 이후에도 중합 반응 이 일어날 수 있도록 일반적으로 저점도의 urethane dimethacrylate (UDMA), triethyleneglycol dimethacrylate (TEGDMA) 등을 혼합한다. ${ }^{23}$ 따라서 이에 따른 결과 분석을 위해 이번 실험에 사용한 복합레진의 구성 성분 을 조사하여 Table 1에 나타내었다. G-aenial Universal Flo의 경우 2,2-bis(4-methacryloxypolyethoxyphenyl) propane (Bis-MEPP), UDMA, TEGDMA 등의 단량체 가 함유 되어 있다는 정보를 얻을 수 있었으나, 스플린트 를 목적으로 개발된 광중합 복합레진인 G-FIX는 시장에 출시된 지 약 2 년이 지난 제품이지만 구성 성분과 함량에 대해 제조사에서 자세한 정보를 제공하지 않았기 때문에 정확한 분석에 어려움이 있었다. 또한 Light-Fix도 국내 출시 직전의 재료로서 구체적인 재료의 구성 성분과 함 량 정보를 얻지 못하였다. 따라서 재료 구성에 따른 실험 결과 분석에는 한계가 있었다.

복합레진의 중합도를 측정하는 방법에는 간접적인 방 법으로 중합을 시행한 후 중합되지 않은 부분을 긁어내 고 남은 부분의 길이를 측정하는 scrape-back length 방 법 ${ }^{24}$ 과 중합 후 상면과 하면의 미세경도를 측정하는 microhardness test방법, ${ }^{20,25}$ 직접적인 방법으로 중합 전과 후 중합체 내부에 남아있는 탄소 이중결합의 수를 측정 하는 infrared spectroscopy 방법 ${ }^{19,20,22,26}$ 등이 있다. Ferracane에 의하면 미세경도값은 탄소 이중결합의 전환율 과 관련이 있어서 중합 중 전환율이 증가하면 미세경도 가 증가되지만 증가값이 절대적으로 전환율과 호환되는 것은 아니라고 하였다. ${ }^{13}$ 하지만 다른 연구에서는 간접적 으로 미세경도를 이용하여 복합 레진의 중합도를 측정하 는 방법이 직접 화학물질을 분석하여 중합도를 측정하는 Fourier transform infrared (FTIR) spectroscopy와 비교 시 서로 유사한 결과를 나타낸다고 하였다. ${ }^{20}$ 따라서 본 연구에서는 중합 정도의 측정으로 간접법인 미세경도법 을 사용하였으나 좀 더 정확한 중합도를 파악하기 위해 서는 별도의 추가 실험이 필요하다.

미세경도는 재료의 작은 부분에 외력을 가하여 변형시 킬 때 나타나는 영구변형에 대한 저항력의 크기로 정의되
며 재료의 강도 및 내마모성을 예측하는데 사용되고 있 다. 이에 영향을 미치는 인자로는 필러의 크기, 형태와 함 량, 단량체의 종류와 비율, 광개시제의 종류, 중합도 등 이 있다. ${ }^{21}$ 통계적으로 분석하지는 않았으나 본 실험 결과 G-aenial Universal Flo의 미세경도값이 전반적으로 다른 2 개의 레진계 재료보다 큰 이유는 필러의 함량과 관계가 있는 것으로 사료된다. 본 연구에서 사용된 복합레진의 구성 성분 정보가 제한되어 있고, 실험 방법 및 재료가 다 른 연구 실험과 다르기 때문에 여러 다른 연구 결과들과 직접적인 비교를 할 수는 없지만, Noh 등 ${ }^{27}$ 의 연구에 의 하면 Filtek Z-350 복합레진이 Tetric N-Ceram bulk fill 레진보다 상면에서 높은 미세경도값을 보인 이유를 필러 함량 차이로 예측하고 있다. 이는 일반적으로 필러의 함 량이 클수록 강한 기계적 성질을 나타내기 때문이다. ${ }^{18,28}$

복합레진에서 충분한 중합이 일어나지 않으면 색 안정 성 및 수복물 물성 저하, 접착력 약화, 중합되지 않은 잔 류 단량체의 타액 내 유리되어 발생되는 연조직 자극 또 는 알러지원 가능성, 치태 침착 유발 가능성 등을 고려할 수 있다. 결국 이러한 결과는 수복물의 실패를 야기할 수 있다. ${ }^{29-31}$ Son 등 ${ }^{32}$ 에 의하면 복합레진 시편의 두께가 증 가할수록 하면은 상면보다 유의하게 낮은 중합도를 보 이는데 이는 중합 깊이와 광조사량의 차이 때문이라고 보고했다. 또한 복합레진의 기질과 관계없이 모든 레진 시편은 두께가 두꺼워질수록 중합률과 미세경도가 직선 적인 감소를 나타내며 이는 선형적 상관관계를 나타낸다 고 하였다. 본 실험에서 사용한 Light-Fix와 G-FIX는 두 께에 상관없이 상면과 하면의 중합도에서 차이를 보이지 않았으나 G-aenial Universal Flo는 $3 \mathrm{~mm}$ 두께부터 낮은 중합도를 보였다. 미세경도값이 높지만 중합도가 낮은 이유로 필러의 영향을 생각해 볼 수 있다. ${ }^{33,34}$ 즉 G-aenial Universal Flo는 이산화규소, 스트론튬 글라스 등의 무기 질 필러를 $69 \%$ 중량비로 함유하고 있어 높은 미세경도 값을 나타낼 수 있으나 이러한 높은 필러값이 중합 광 투 과를 어렵게 하므로 중합정도가 낮아진다고 볼 수 있다. 결과적으로 스플린트 전용 레진인 Light-Fix와 G-FIX는 임상에서 적용 시 충분한 중합도를 가진다고 생각할 수 있다. Yoo 등 ${ }^{35}$ 에 의하면 G-FIX는 유동성 복합레진과 수 복용 복합레진과의 비등한 굴곡 강도를 보이고 상대적으 로 낮은 탄성계수를 보여 동요치 고정에 유리한 레진 재 료임을 보고하였다.

본 연구는 시편수가 적고 간접적인 방법으로 중합도를 평가한 한계점이 있지만, 이번 실험 결과가 향후 임상적으 
로 사용하게 될 새로운 광중합 레진 스플린팅 재료들의 개발에 있어 참조할 수 있는 자료가 될 것으로 생각된다.

\section{결론}

스플린팅 전용 레진계 재료인 Light-Fix와 G-FIX는 5 $\mathrm{mm}$ 두께까지 적절한 광중합이 가능할 것으로 사료된다.

\section{Acknowledgements}

이 논문은 2017년도 강릉원주대학교 치과병원 협동임 상연구비(CR1702) 지원에 의하여 수행되었다.

\section{ORCID}

Jeong-Gil Lee https://orcid.org/0000-0001-9656-4027

Soo-Yeon Kim https://orcid.org/0000-0001-7437-6877

Jae-Kwan Lee https://orcid.org/0000-0003-1710-1580

Jin-Woo Kim https://orcid.org/0000-0002-0004-0710

Se-Hee Park https://orcid.org/0000-0002-4052-4082

Kyung-Mo Cho https://orcid.org/0000-0003-3464-9425

\section{References}

1. Bernal G, Carvajal JC, Muñoz-Viveros CA. A Review of the Clinical Management of Mobile Teeth. J Contemp Dent Pract 2002;3:10-22.

2. Watts A, Addy M. Tooth discolouration and staining: a review of the literature. Br Dent J 2001;190:30916.

3. Ferencz JL. Splinting. Dent Clin North Am 1987; 31:383-93.

4. Smales RJ, Webster DA. Restoration deterioration related to later failure. Oper Dent 1993;18:130-7.

5. Burcak Cengiz S, Stephan Atac A, Cehreli ZC. Biomechanical effects of splint types on traumatized tooth: a photoelastic stress analysis. Dent Traumatol 2006;22:133-8.

6. Oikarinen K. Comparison of the flexibility of various splinting methods for tooth fixation. Int J Oral Maxillofac Surg 1988;17:125-7.

7. Andreasen JO, Andreasen FM, Mejàre I, Cvek M. Healing of 400 intra-alveolar root fractures. 2. Effect of treatment factors such as treatment delay, repositioning, splinting type and period and antibiotics. Dent Traumatol 2004;20:203-11.

8. Neaverth EJ, Georig AC. Technique and rationale for splinting. J Am Dent Assoc 1980;100:56-63.

9. Kahler B, Heithersay GS. An evidence-based appraisal of splinting luxated, avulsed and rootfractured teeth. Dent Traumatol 2008;24:2-10.

10. Mazzoleni S, Meschia G, Cortesi R, Bressan E, Tomasi C, Ferro R, Stellini E. In vitro comparison of the flexibility of different splint systems used in dental traumatology. Dent Traumatol 2010;26:30-6.

11. Liu X, Zhang Y, Zhou Z, Ma S. Retrospective study of combined splinting restorations in the aesthetic zone of periodontal patients. Br Dent J 2016;220:241-7.

12. Aggstaller H, Beuer F, Edelhoff D, Rammelsberg $\mathrm{P}$, Gernet W. Long-term clinical performance of resin-bonded fixed partial dentures with retentive preparation geometry in anterior and posterior areas. J Adhes Dent 2008;10:301-6.

13. Ferracane JL. Correlation between hardness and degree of conversion during the setting reaction of unfilled dental restorative resins. Dent Mater 1985;1:11-4.

14. Vankerckhoven H, Lambrechts P, van Beylen M, Davidson CL, Vanherle G. Unreacted Methacrylate Groups on the Surfaces of Composite Resins. J Dent Res 1982;61:791-5.

15. Cook WD, Standish PM. Cure of resin based restorative materials. II. White light photopolymerized resins. Aust Dent J 1983;28:307-11.

16. Gonçalves F, Pfeifer CC, Stansbury JW, Newman SM, Braga RR. Influence of matrix composition on polymerization stress development of experimental composites. Dent Mater 2010;26:697-703.

17. Pilo R, Cardash HS. Post-irradiation polymerization of different anterior and posterior visible lightactivated resin composites. Dent Mater 1992;8:299304.

18. Hofmann N, Papsthart G, Hugo B, Klaiber B. Comparison of photo-activation versus chemical or dual-curing of resin-based luting cements regarding flexural strength, modulus and surface hardness. J Oral Rehabil 2001;28:1022-8.

19. Asmussen E. Factors affecting the quantity of re- 
maining double bonds in restorative resin polymers. Scand J Dent Res 1982;90:490-6.

20. Rueggeberg FA, Craig RG. Correlation of parameters used to estimate monomer conversion in a light-cured composite. J Dent Res 1988;67:932-7.

21. Abed YA, Sabry HA, Alrobeigy NA. Degree of conversion and surface hardness of bulk-fill composite versus incremental-fill composite. Tanta Dent J 2015;12:71-80.

22. Moraes LG, Rocha RS, Menegazzo LM, de Areaújo EB, Yukimiti K, Moraes JC. Infrared spectroscopy: a tool for determination of the degree of conversion in dental composites. J Appl Oral Sci 2008;16:145-9.

23. Gajewski VE, Pfeifer CS, Fróes-Salgado NR, Boaro LC, Braga RR. Monomers used in resin composites: degree of conversion, mechanical properties and water sorption/solubility. Braz Dent J 2012;23:50814.

24. Cook WD. Factors affecting the depth of cure of UVpolymerized composites. J Dent Res 1980;59:800-8.

25. DeWald JP, Ferracane JL. A comparison of four modes of evaluating depth of cure of light-activated composites. J Dent Res 1987;66:727-30.

26. Asmussen E. Restorative resins: hardness and strength vs. quantity of remaining double bonds. Scand J Dent Res 1982;90:484-9.

27. Noh T, Song E, Park S, Pyo A, Kwon Y, Kim J, Kim S, Jeong T. Comparison of the Mechanical Properties between Bulk-fill and Conventional Composites. J Korean Acad Pediatr Dent 2016;43:365-73.

28. Fonseca RB, de Almeida LN, Mendes GA, Kasuya
AV, Favarão IN, de Paula MS. Effect of short glass fiber/filler particle proportion on flexural and diametral tensile strength of a novel fiber-reinforced composite. J Prosthodont Res 2016;60:47-53.

29. Ilie N, Jelen E, Clementino-Luedemann T, Hickel R. Low-shrinkage composite for dental application. Dent Mater J 2007;26:149-55.

30. Loguercio AD, Reis A, Schroeder M, Balducci I, Versluis A, Ballester RY. Polymerization shrinkage: effects of boundary conditions and filling technique of resin composite restorations. J Dent 2004;32:459-70.

31. de Gee AJ, ten Harkel-Hagenaar E, Davidson CL. Color dye for identification of incompletely cured composite resins. J Prosthet Dent 1984;52:626-31.

32. Son SA, Kim HC, Hur B, Seol HJ, Kwon YH, Kim HI, Park JK. Influence of Resin Thickness on the Degree of Conversion and Microhardness of Silorane-based Composite Resin. Korea J Dent Mater 2012;39:57-64.

33. Hofmann N, Papsthart G, Hugo B, Klaiber B. Comparison of photo-activation versus chemical or dual-curing of resin-based luting cements regarding flexural strength, modulus and surface hardness. J Oral Rehabil 2001;28:1022-8.

34. Ruyter IE, Oysaed H. Conversion in different depths of ultraviolet and visible light activated composite materials. Acta Odontol Scand 1982;40:179-92.

35. Yoo JI, Kim SY, Batbayar B, Kim JW, Park SH, Cho KM. Comparison of flexural strength and modulus of elasticity in several resinous teeth splinting materials. J Dent Rehabil Appl Sci 2016;32:169-75. 


\section{레진계 치아 스플린팅 재료들의 중합능력 평가}

\section{이정길 ${ }^{1}$, 김수연 ${ }^{1}$, 이재관 ${ }^{2}$, 김진우 $^{1}$, 박세희 $^{1}$, 조경모 ${ }^{1 *}$}

1강릉원주대학교 치과대학 치과보존학교실

${ }^{2}$ 강릉원주대학교 치과대학 치주과학교실

목적: 본 연구의 목적은 치아 스플린팅에 사용되는 레진계 재료들의 두께에 따른 중합 능력을 평가하는 것이다.

연구 재료 및 방법: 레진계 스플린팅 재료로 개발된 Light-Fix와 G-FIX, 수복용과 스플린트용으로 사용 가능한 고흐름 성 복합레진인 G-aenial Universal Flo를 사용하여 직경 $5 \mathrm{~mm}$, 두께 2,3, 4, $5 \mathrm{~mm}$ 의 시편을 각각 10 개씩(총 120 개) 제작 하였다. 비커스 경도 측정기를 이용하여 시편 상면과 하면의 미세경도값을 측정하였다. 각 두께에서 복합레진의 중합정 도를 95\% 유의수준에서 independent T-test를 이용하여 통계적으로 분석하였다.

결과: Light-Fix와 G-FIX는 두께에 상관없이 중합도의 차이를 보이지 않았다. G-aenial Universal Flo는 $3 \mathrm{~mm}$ 두께부터 유의하게 낮은 중합도를 보였다.

결론: 스플린팅 전용 레진계 재료인 Light-Fix와 G-FIX는 $5 \mathrm{~mm}$ 두께까지 적절한 광중합이 가능할 것으로 사료된다.

(구강회복응용과학지 2018;34(4):290-6)

주요어: 복합레진 스플린트; 미세경도; 중합능력; 치아 동요

*교신저자: 조경모

(25457)강원도 강릉시 죽헌길 7 강릉원주대학교 치과대학 치과보존학교실

Tel: 033-640-3155 | Fax: 033-640-3103 || E-mail: drbozon@gwnu.ac.kr

접수일: 2018년 10월 20일 | 수정일: 2018년 11월 5일 | 채택일: 2018년 11월 12일 